\title{
DIFFERENTIATED ASSESSMENT OF ANXIETY IN ELDERLY WOMEN
} Anatolii Vladimirovich Gribanov ${ }^{1}$, Irina Sergeevna Deputat ${ }^{2}$, Yulia Sergeevna Dzhos ${ }^{3}$, Alexandra Nikolaevna Nehoroshkova ${ }^{4}$, Irina Leopolidovna Bolshevidtseva ${ }^{5}$, Yana Vladimirovna Kereush ${ }^{6}$, Irina Nikolaevna Deryabina ${ }^{7}$, Larisa Fedorovna Startseva ${ }^{8}$, Tatyana Valerjevna Emeljyanova ${ }^{9}$, Tatyana Vladimirovna Bagretsova $^{10}$, Irina Victorovna Ikonnikova $^{11}$

Abstract: The article presents the results of a study designed to assess the anxiety and an analysis of its individual components in 104 elderly women. Summary of the data obtained shows that women between ages 55-64 years have higher anxiety in comparison with older women (65-74 years of age). This is due to emotional difficulties associated with a person's transition to old age. The anxiety is expressed as emotional discomfort indicators and in anxious assessment of near-term perspective. High indication of asthenic symptoms were present in both age groups, which is likely to be associated not only with the manifestation of anxiety but also with a separate state characterizing the elderly.

UDC Classification: 612.67, 159.9.072.43, DOI: http://dx.doi.org/10.12955/cbup.v3.612

Keywords: anxiety, old age, characteristics of trait anxiety

\section{Introduction}

The problem of maximal preservation of functional capacities of an organism during gerontogenesis is becoming increasingly important at the present. The modern concept of gerontology and geriatrics is focused on providing medical and social assistance to elderly people by taking into account not only their existing chronic disease, but also other factors potentially or actually limiting the life activity of aging people.

One of the factors that has a major impact on neuropsychic state of the person with old age is the presence anxiety disorders (Avedisova, Borodin, \& Aldushin, 2007; Bruce, Yonkers, \& Otto, 2005). Anxiety disorders often are regarded as characteristics of old age in the modern practical medicine (Kraeva, 2006). It is believed that anxiety is the basis of a range of developmental disorders, leading to a variety of negative changes in the functional state, reducing the capacity for attention, concentration, and mental capacity, impairing retrieval of information, and impairing associative thinking. Therefore, the identification of high level of anxiety in the elderly and timely prevention of possible negative consequences of its effects on the organism during gerontogenesis are especially important.

Anxiety as a mental phenomenon is characterized by a complex structure and associated with neuroendocrine, somatic-visceral, and psychological levels of human activity. In this regard, it should be considered, more reasonably, as a system and an integral phenomenon. At the same time, we can state for a fact that a significant integration in theory and research strategy for the study of anxiety is not observed today. Research papers devoted to differentiated assessment of anxiety in the elderly are virtually absent in the scientific literature.

\footnotetext{
1 Anatolii Vladimirovich Gribanov, Northern (Arctic) Federal University named after M.V. Lomonosov (NArFU), Russia, a.gribanov@narfu.ru

${ }^{2}$ Irina Sergeevna Deputat, NArFU, Russia, i.deputat@narfu.ru

${ }^{3}$ Yulia Sergeevna Dzhos, NArFU, Russia, u.jos@narfu.ru

${ }^{4}$ Alexandra Nikolaevna Nehoroshkova, NArFU, Russia, a.nehoroshkova@narfu.ru

${ }^{5}$ Irina Leopolidovna Bolshevidtseva, NArFU, Russia, irana1307@mail.ru

${ }^{6}$ Yana Vladimirovna Kereush, NArFU, Russia, yana.kereush@mail.ru

${ }^{7}$ Irina Nikolaevna Deryabina, NArFU, Russia, irinaneuro@yandex.ru

${ }^{8}$ Larisa Fedorovna Startseva, NArFU, Russia, 1.starceva@ narfu.ru

${ }^{9}$ Tatyana Valerjevna Emeljyanova, NArFU, Russia, t.emeljyanova@narfu.ru

${ }^{10}$ Tatyana Vladimirovna Bagretsova, NArFU, Russia,t.bagretsova@narfu.ru

${ }^{11}$ Irina Victorovna Ikonnikova, NArFU, Russia, i.ikonnikova@narfu.ru
} 
The aim of our study was the assessment of anxiety and the analysis of the expression of its individual components in older women.

\section{Methods}

This study was conducted involving 104 elderly women. The participants were divided into two age groups: the first group consisted of women between ages 55-64 (60 people), and the second consisted of women between ages 65-74 (44 persons), in according with generally accepted WHO classification and the classification of the American researcher D. J. Bouge (Bouge, 1969). This classification marks the specifics of the elderly social adaptation in the pre-retirement period.

For an individual assessment of anxiety, every woman, in both groups, was given an integrative anxiety test (IAT) developed in the laboratory of clinical psychology, V. M. Bekhterev Psychoneurological Research Institute, in St. Petersburg (Bizyuk, Wasserman, \& Iovlev, 2005).

The structure of the research methodology includes two subtests designed for differential diagnosis of alarm and anxiety. Both subtests contain 5 subscales characterizing the individual components of these emotional states:

1. Subscale "emotional discomfort" characterizes the severity of a person's emotional tension, reduced emotional background or dissatisfaction with life situation, and elements of agitation.

2. Subscale "asthenic component" reflects the severity of a person's fatigue, sleep disorders, lethargy, and passivity.

3. Subscale "phobic component" describes the severity of a person experiences some unappreciated threats, self-doubt, and self-worthlessness.

4. Subscale "anxious assessment of near-term perspective" reflects the severity of a human projection of fears into perspective, and general concern for the future.

5. Subscale "social protection" describes the manifestations of anxiety in social contacts or attempts of the subject to consider the social sphere as a major source of stress and anxiety self-doubt.

The test contains 30 statements with four-choice answers to the respondent for which points are awarded. The transfer of raw scale scores of overall anxiety and subscales, on a nine-point scale (stanine), according to the existing pattern of diagnostic ratios, is provided for standardization of the results. A high level of anxiety match 7-9 stanines, average 4-6 stanines, and low level 1-3 stanines.

Statistical analysis was performed with SPSS 21 for Windows. The measured parameters were found not to be normally distributed (Shapiro-Wilk test). Chi-square test was performed to reveal the differences in qualitative characteristics between the comparative groups. The Mann-Whitney U-test was used for descriptive statistics of quantitative indicators; median and range of values from the first to the third quartile were performed. Correlation analysis was used to identify the relationships between the studied variables. Due to the fact that the variables in all compared groups did not follow the normal distribution, Spearman's correlation was chosen for the analysis. Probability values of 0.05 (two-tailed) were considered statistically significant.

\section{Results and discussion}

A person transitioning to old age often views this period as a time of crisis in life. This is often accompanied by emotional experiences, hypochondriasis, and psychosomatic diseases (Smulevich, Andryushchenko, \& Romanov, 2006). The results of our study also showed a more pronounced anxiety in women between ages 55-64 compared with older women between ages 65-74 (Figure 1). 
Situational anxiety indicators of elderly women, reflecting the emotional state at the time of the study, do not differ between both age groups, whereas personal anxiety indicators, as stable characteristics in women of age 55-64, exceed the value of this indicator for women of age 65-74.

The initial period of the elderly is characterized by significant changes from the previous time period in life. These changes may be associated with external factors (the official retirement, the emergence of excess free time, previous employment, changing social status, etc.) and internal factors (awareness of age-related decline in physical and mental strength, passive-dependent position of society and family, etc.). Such changes in life stereotypes and emotional relationships can certainly manifest in a constant experience of anxiety even in response to unimportant circumstances, and solidify in the form of personal anxiety.
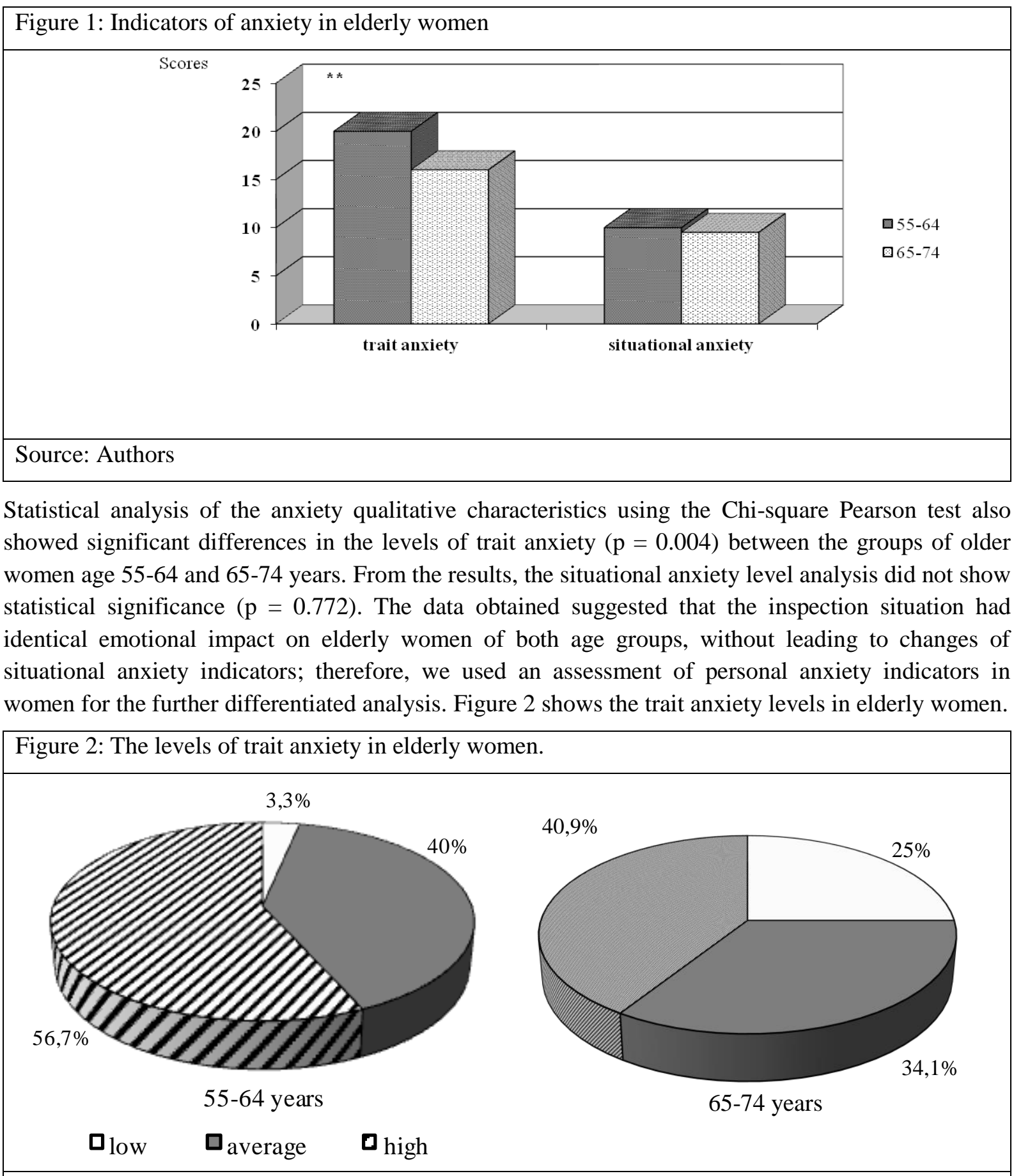

Source: Authors 
The study showed that in both age groups, women with high level of anxiety are most prominent. These data once again underline the fact that advance in age is a critical period in human life on all of its account. Change in social situation associated with retirement, the failure to meet certain requirements, need of valuable orientation change for the new period of the life all affect the general psychological state of an elderly person in the form of emotional unrest and anxiety. At the same time, the results of the research suggested that the tendency of having high anxiety still remains for elderly women in the later period of their life as well. It is known that adaptation to changes and compensatory opportunities associated with aging are closely tied to a decrease in the general mental reactivity of an organism. Thus, the resistance to stressful factors decreases, while the rough and tumble of life is hardly transferred (Satina \& Krasnova, 2003). Anxiety raises and fixes, as steady personal quality, against the background of growing emotional instability and intensity.

The analysis of the results obtained also testifies to the fact that the number of elderly women with low level of anxiety in the 65-74 age is greater than those in the 55-64 age group by almost eight times at $25 \%$ and $3.3 \%$, respectively. At the same time, it is known that a certain optimal level of anxiety adequate for detecting threats in real-life situations, the so-called "useful anxiety," is necessary for an effective adaptation to reality (Himadi, 1996). The useful anxiety plays a positive role, not only as the indicator of possible dangers, but also as a mobilizer of mental reserves to start the most effective mechanisms of behavioral reaction (Mei, 2001). The key moment that triggers an anxiety condition is based on the processes of threat assessment associated with the situational analysis the individual's attitude toward the situation. These processes have complex characteristics; they include not only simple perceptual functions, but also memory processes, ability to perform abstract thinking, updates from last experience, skills, etc. Quite possibly, the decrease in anxiety to low level noted in women of an older age group caused by structural complexity of this phenomenon and by a decrease in functionality of higher nervous activity from the aging process.

The data obtained in the analysis of individual components of trait anxiety in elderly women deserve the special attention (Table 1).

Table 1: Intensity components of trait anxiety in elderly women on a scale, Median (Q1-Q3)

\begin{tabular}{|l|c|r|r|}
\hline \multicolumn{1}{|c|}{$\begin{array}{c}\text { Components of trait } \\
\text { anxiety }\end{array}$} & $\begin{array}{c}\mathbf{5 5 - 6 4} \text { years } \\
(\mathbf{n = 6 0})\end{array}$ & $\begin{array}{c}\text { 65-74 years } \\
(\mathbf{n = 4 4 )}\end{array}$ & $\begin{array}{c}\text { Probability value } \\
(\mathbf{p})\end{array}$ \\
\hline Emotional discomfort & $151(106-193)$ & $100(75-151)$ & 0,010 \\
\hline Asthenic component & $140(100-195)$ & $140(83-200)$ & 0,804 \\
\hline Phobic component & $66(29-103)$ & $47(0-94)$ & 0,001 \\
\hline $\begin{array}{l}\text { Anxious assessment of } \\
\text { near-term perspective }\end{array}$ & $163(130-200)$ & $124(64-165)$ & 0,891 \\
\hline Social protection & $143(100-168)$ & $143(90-171)$ & \\
\hline
\end{tabular}

Source: Authors

Table 1 shows that the emotional discomfort indicators and anxious assessment of near-term perspective in women of the 55-64 age group were significantly higher than those in women of the 6574 age group, if the transfer levels are high and medium, respectively. In our opinion, it once again confirms the emotional complexity associated with age transition into an elderly state. Of course, the process of consciousness restructuring associated with the retirement occurs in different ways. However, the emotional experience connected to a reduction in the income level, a decrease in social support, and development of diseases compared with older age group is common among most of the people in early stages of senility (Schimer \& Kahana, 1992). These experiences, in turn, cause an 
increase in anxiety in the assessment of near-term perspective and the negative subjective emotions in an elderly person.

Uncertainty in the future and negative emotional experiences can provoke the appearance of any fear and phobia. Table 1 shows that, despite a lack of statistical significance, the personal anxiety phobic component in elderly women at age 55-64 is also higher than that of the women in the 65-74 age group. Kolchina (2011) noted that the most typical fears with aging are fear of the future, inevitable "diseases of old age," and the fear of death. Probably, these fears are experienced more sharply at the moment of change from habitual life stereotypes. However, they also occur in the later period for the elderly, so statistical significance was not found.

A high level of asthenic component is revealed in both age groups during the study. The received scores also correspond to high levels of anxiety in both the 55-64 and 65-74 age groups. Averbuch \& Teleshevskaya (1976) noted that changes caused by aging, physiological processes, which are not the primary diseases can still lead to limited functionality of the organism and reduce its resistance to harmful influences. This is reflected in the general somatic condition. Weakness, fatigue, emotional lability, hyperesthesia, and sleep disorders are peculiar conditions for an elderly person. In our view, a high level of this component in the elderly can be considered not only as a manifestation of personal anxiety, but also as an independent state, due to a decrease in the intensity of metabolic processes and physical activity, changes in the immune, and neuroendocrine systems of the organism resulting from aging.

The study did not reveal significant differences in this component of trait anxiety as a social protection reaction between elderly women. Both age groups correspond to a normal level of anxiety according to indicators on the scale. Therefore, the social environment is not considered as the main source of disturbing tension and lack of self-confidence by elderly people.

Most probably, the changes at the social level related to retirement, orientation changes for each individual person, social status changes, and integration and judgment based on past lift experience all lead to the fact that anxiety in social contacts does not have a paramount characteristic in old age.

\section{Conclusion}

The results obtained during the study showed that women at age 55-64 have a higher anxiety level compared to older women (age 65-74 years). This is due to emotional difficulties associated with the transition to an older age. This anxiety is expressed as an increase in the level of emotional discomfort indicators and anxious assessment of near-term perspective. A high level of asthenic component was found in both age groups, which is likely to be associated not only with the manifestation of anxiety, but also as a separate state, characterizing the elderly.

\section{Acknowledgement}

This research work was performed as part of the state task project in the field of scientific activities for the Ministry of Education and Science of the Russian Federation for 2014-2016, № 2025 Northern (Arctic) Federal University named after M.V. Lomonosov. 


\section{References}

Avedisova, A. S., Borodin, V. I., \& Aldushin, A. A. (2007). The ratio of patients with borderline mental disorders to the possibility of occurrence of various adverse events during psychopharmacological treatment. Psychiatry and Pharmacotherapy, 9(6), 4-10.

Averbuch, E. S., \& Teleshevskaya M. E. (1976). Nevrozy i nevrozopodobnye sostojanija v pozdnem vozraste [Neuroses and pseudoneurosis states in elderly]. Leningrad, Russia: Medicine.

Bizyuk, A. P., Wasserman, L. I., \& Iovlev, B. V. (2005). Primenenie integrativnogo testa trevozhnosti [Application of integrative anxiety test]. St. Petersburg, Russia.

Bouge, D. J. (1969). Principles of demography. New York: J. Wiley.

Bruce, S. E., Yonkers, K. A., \& Otto, M. W. (2005). Influence of psychiatric comorbidity on recovery and recurrence in generalized anxiety disorder, social phobia, and panic disorder: a 12-year prospective study. American Journal of Psychiatry, 162(6), 1179-1187.

Himadi, W. (1996). Safety signals and agoraphobia. Journal of Psychiatry, 153(4), 503-512.

Kolchina, T. V. (2011). Strahi u pozhilyh ljudej. Organizacija psihologicheskoj pomoshhi [Fears among the elderly. Organization of psychological service]. Volgograd, Russia: Volgograd Regional Gerontology Center.

Kraeva, M. A. (2006). Osobennosti lichnosti pacientov pozhilogo vozrasta s sosudistymi zabolevanijami (v svjazi s zadachami psihologicheskoj reabilitacii) [Personality characteristics of elderly patients with vascular disease (in connection with problems of psychological rehabilitation)]. St. Petersburg, Russia: SPMA.

Mei, R. (2001). Smysl trevogi [Meaning of anxiety]. Moscow, Russia: Medicine.

Satina, L. V., \& Krasnova, O. V. (2003). Depressija pozdnego perioda zhizni: gore i oslozhnenija, svjazannye s nim v pozhilom vozraste: rasshirennyj referat. Psihologija starosti $i$ starenija [Late-life depression: grief and complications associated with him in the elderly: an extended abstract psychology of old age and aging]. Moscow, Russia: Academy.

Schimer, M. R., \& Kahana, J. S. (1992). Legal issues in the care of the older adults. Ohio: Northeastern Ohio Universities of Medicine.

Smulevich, A. B., Andryushchenko, A. V., \& Romanov D. V. (2006). Therapy of borderline mental disorders (study of the efficacy and tolerability afobazole). Mental disorders in general medicine, 6, 10-16. 